\title{
Using multilist designs to test for contextual reinstatement effects in recognition
}

\author{
MICHAEL S. HUMPHREYS, RAY PIKE, JOHN D. BAIN, and GERALD TEHAN \\ University of Queensland, St. Lucia, Queensland, Australia
}

\begin{abstract}
Gillund and Shiffrin (1984) proposed an explanation for the lack of a contextual matching advantage in recognition. We found that although their theory can predict no effect in a single-list design, it generally predicts an effect in a multilist design. An experiment to test this prediction was inconclusive, because the contextual manipulation used (study room) was not shown to have reliable effects.
\end{abstract}

It is a common assumption that recognition memory tasks require subjects to restrict their judgments to events that occurred at a designated time and place (Anderson \& Bower, 1972; Humphreys \& Bain, 1983). The unresolved problem for memory theorists is how this feat is accomplished, particularly given that most context manipulations have little or no effect on recognition (Eich, 1980; Godden \& Baddeley, 1980; Smith, Glenberg, \& Bjork, 1978). Gillund and Shiffrin (1984) proposed a solution to this problem by assuming that the match of study and recognition contexts increases both the mean and variance of matching strengths, so that there is no net gain in discriminability. We show that this explanation does not generally succeed with multilist designs, in which different lists are studied in different contexts and then all lists are tested in one of the study contexts.

Assume a subject studies a list of words $A_{1}, A_{2}, \ldots$, $A_{k}$ in context $X_{1}$, studies a second list $B_{1}, B_{2}, \ldots, B_{k}$ in context $X_{2}$, and is then tested for the recognition of items from both lists in context $X_{1}$. Furthermore, assume that subjects are encouraged to learn individual words, not interword associations, and that list words and distractors are randomly drawn from a common pool of items. Under these assumptions, Gillund and Shiffrin's (1984) model represents the memory as a set of $2 k$ images, one for each item in each list. As a result of the study trial, the association between an item and its image (the self association) is strengthened, as is the association between the context and each image. In addition, there is a preexisting association between any two items. We represent the $e x-$ pected strength of the self association, the same-context association, the different-context association, and the preexisting association as $a, x_{s}, p x_{s}$, and $d$, respectively.

The expected same-context old-item $(S)$, differentcontext old-item $(D)$, and new-item $(N)$ matching strengths are given in Equations 1, 2, and 3, respectively:

This work was supported by a grant from the Australian Research Grants Scheme to the first three authors. Reprint requests should be sent to Michael S. Humphreys, Department of Psychology, University of Queensland, St. Lucia, Queensland, Australia 4067.

$$
\begin{aligned}
S & =x_{s} a+(k-1) x_{s} d+p k x_{s} d \\
D & =p x_{s} a+k x_{s} d+p(k-1) x_{s} d \\
N & =k x_{s} d+p k x_{s} d
\end{aligned}
$$

Under Gillund and Shiffrin's (1984) assumptions, the variance of the same-context old-item matching strength $\left(\sigma_{s}^{2}\right)$ would be greater than the variance of the differentcontext old-item matching strength $\left(\sigma_{d}^{2}\right)$. In a multilist design, unlike in a single-list design, this does not, in general, eliminate the contextual matching advantage. So the reader can see this, we show the expressions for $d_{a}$ in Equations 4 and 5 ( $\sigma_{n}^{2}$ is the variance of the new-item matching strength):

$$
d_{a}\left(\text { same context) }=\frac{x_{s} a-x_{s} d}{\left[\left(\sigma_{s}^{2}+\sigma_{n}^{2}\right) / 2\right]^{1 / 2}},\right.
$$

where the numerator is Egn 1 - Egn 3, and

$$
d_{a}(\text { different context })=\frac{p\left(x_{s} a-x_{s} d\right)}{\left[\left(\sigma_{d}^{2}+\sigma_{n}^{2}\right) / 2\right]^{1 / 2}},
$$

where the numerator is Egn 2 - Egn 3.

The numerator in Equation 5 is $p$ times the numerator in Equation 4, but $\sigma_{n}^{2}$ appears in the denominator in both equations, and $p^{2} \sigma_{s}^{2}<\sigma_{d}^{2}$ (see the Appendix). Thus the denominator in Equation 5 is considerably more than $p$ times the denominator in Equation 4. Therefore, the ability to discriminate the same-context old items from the new items is, in general, greater than the ability to discriminate the different-context old items from the new items. It is possible, however, that if only one point on the ROC curve is observed, this difference in discriminability may be missed. As an alternative to generating a complete ROC curve, it is possible to directly test the assumption that produces a larger variance for a samecontext match than for a different-context match, that is, the assumption that the variance in a parameter is proportional to the mean parameter value.

To test this assumption, we consider a situation in which one of the two lists contains $l k$ items $(l$ is an integer greater than 1) and the other list contains $k$ items. It is easy to 
show that the matching stengths for all items are larger by the amount $(l-1) k d\left(x_{s}-x_{d}\right)$ when they are tested in the context in which the longer list was studied rather than in the context in which the shorter list was studied (in other words, there is no change in mean matching strength differences relative to the equal list length case). Note, also, that if the variance of the contextual parameter increases along with an increase in its strength, then not only are the expected matching strengths higher when the test is in the context of the longer list, but so too are the variances. As a result, the discriminability between samecontext, different-context, and new-item matching strengths should be smaller when the test is in the study context of the longer list than when it is in the study context of the shorter list.

We elected to test these predictions with a two-list design in which study room was the context manipulation. This manipulation seemed particularly appropriate because of Smith's (1985) report of a small effect of study room reinstatement on recognition in a multilist design, contrary to the general finding of no effect with singlelist designs. The procedure involved two lists, one short (40 items) and one long ( 200 items). Each list was studied in its own distinctive context. An attempt was made to keep all details other than the number of rooms the same as in Smith's study (Smith used five rooms), although Smith (personal communication) indicated that his subjects, unlike ours, were not informed in advance that they would be learning lists in different rooms.

\section{METHOD}

Subjects

Forty-eight subjects participated in this experiment. They were introductory psychology students at the University of Queensland who served as part of a course requirement.

\footnotetext{
Materials

The word pool used to construct the study and test lists consisted of 310 high-frequency words (KuČera \& Francis, 1967; frequency $>100$ ). The words were nouns, verbs, and adjectives. No function, plural, pasttense, or denial words were used. Two sets of 40 words (Set A and Set B) were sampled without replacement to form the two short study lists. An additional 160 words (Set $C$ ) were sampled to be used as fillers on the two long study lists. The two long lists were formed by appending the 160 filler items to the two short lists. Thus, the 40 words on the short lists were identical to and in the same position as the first 40 words in the corresponding long lists. On the two long lists, the first 40 words were different and the last 160 words were identical. An additional 70 words were sampled to be used as the distractors on the recognition test. The old items on the recognition test were the first 35 words of the $\mathbf{4 0}$ items from Set A and the first $\mathbf{3 5}$ items from Set B. Thus the recognition test consisted of 140 words presented in a random fashion.

\section{Design and Procedure}

The subjects studied a 40 -item list in one room and a 200 -item list in another room. They were then tested for recognition in one of the two study rooms. The two rooms differed on a number of dimensions. One room had the general appearance of a small classroom, except that it was windowless. This room was bare except for some tables, chairs, and a chalkboard. The ceiling and walls of the room were painted white. The second room was a vision research laboratory that was painted entirely black. The tables and benches in this room were laden with equipment of various kinds; the overall clutter provided a sharp contrast to the spartan furnishings of the white room.
}

The subjects were told that they were to learn two lists of words and that each list would be learned in a different room. The lists were taperecorded in a female voice and presented at a 3-sec rate. After the first list was presented, the experimenter escorted the small group of subjects (generally 3 but sometimes fewer) to the second room. After the second list had been studied, the subjects left the room and then returned either to the first or second room for the yes/no recognition test. The subjects were instructed to respond "yes" if the test item had occurred in either room and "no" otherwise.

The order of presentation for materials, list length, study room, and test room were counterbalanced to produce a total of 16 between-subject conditions. An alpha level of .05 was used in all subsequent analyses.

\section{RESULTS}

The subjects readily discriminated between old and new words, as is evident in Table 1. Collapsed across all conditions, the mean hit rate was .664 and the mean false alarm rate was .291. The mean standard errors associated with these overall means were .030 and .032 , respectively. The effect of the reinstatement of study context was more important for present purposes. No hint of a context effect was apparent. Items that were studied and tested in the same room had a slightly lower hit rate (.659) than those words that were studied in one room but tested in the other (.671). This difference was far from significant $[F(1,32)=.293, M S e=.012]$, and context did not interact with any other variable.

To gauge whether the variances of the matching strengths were greater when the test was in the context of the long list than when it was in the context of the short list, $d$ 's were calculated for each subject and submitted to a $2 \times 2 \times 2 \times 2$ analysis of variance involving the same variables as in the first analysis. When the test occurred in the context of the long list, the average $d^{\prime}$ was 1.13 for items from the long list (match condition) and 1.07 for items from the short list (mismatch condition). When the test occurred in the context of the short list, the $d^{\prime}$ s for items from the long (mismatch) and short (match) lists were 1.09 and .95 , respectively. The difference between the averages of the long and short list contexts was not significant $[F(1,32)=2.50, \mathrm{MSe}=.10]$. Somewhat anomalously, the $d^{\prime}$ s appeared larger for items from long lists than for items from short lists. This difference, however, was not significant $[F(1,32)=.36, M S e=.43]$.

\section{DISCUSSION}

In a subsequent experiment (Bain, Humphreys, Tehan, \& Pike, 1987), we tried to establish that the reinstatement of room context would affect recall performance. We could find no such effect using our procedures and materials. It appears that our subjects were simply not using room context to distinguish between list memories and other memories.

Table 1

Probability of Recognition as a Function of Study Room (SR) and Test Room (TR)

\begin{tabular}{lcccccc}
\hline & \multicolumn{4}{c}{ Hits } \\
\cline { 2 - 3 } \cline { 5 - 6 } \cline { 5 - 6 } \cline { 5 - 6 } & \multicolumn{2}{c}{ Long List } & & \multicolumn{2}{c}{ Short List } & \\
\cline { 2 - 3 } \cline { 5 - 6 } White SR & Black SR & & White SR & Black SR & False Alarms \\
\hline White TR & .669 & .705 & & .628 & .687 & .303 \\
Black TR & .621 & .726 & & .672 & .621 & .281 \\
\hline
\end{tabular}


Our results thus support Fernandez and Gienberg's (1985) results, which indicate that there is at best a small and inconsistent effect of reinstating the study room on memory perormance. This inability to show that room context was being used in any paradigm means, however, that we were unable to test our derivations from Gillund and Shiffrin's (1984) theory. Nevertheless, investigators employing more reliable contextual manipulations (e.g., extreme environmental changes or drug states) should consider testing recognition with a multilist design.

\section{REFERENCES}

ANDERSON, J. R., \& BowER, G. H. (1972). Recognition and retrieval processes in free recall. Psychological Review, 79, 97-123.

Bain, J. D., Humphreys, M. S., Tehan, G., \& Pike, R. (1987). Why psychologists cannot recognize: The importance of context. Unpublished manuscript, University of Queensland, St. Lucia, Queensland, Australia.

EicH, J. E. (1980). The cue-dependent nature of state-dependent retrieval. Memory \& Cognition, 8, 157-173.

Fernandez, A., \& GlenberG, A. M. (1985). Changing environmental context does not reliably affect memory. Memory \& Cognition, 13, 333-345.

Gillund, G., \& ShifFrin, R. M. (1984). A retrieval model for both recognition and recall. Psychological Review, 91, 1-67.

GodDEN, D. R., \& BADDELEY, A. D. (1980). When does context influence recognition memory? British Journal of Psychology, 71, 99-104.

HumPhreys, M. S., \& Bain, J. D. (1983). Recognition memory: A cue and information analysis. Memory \& Cognition, 11, 583-600.

Humphreys, M. S., Pike, R., Bain, J. D., \& Tehan, G. (1987). Global matching: A comparison of the SAM, Minerva, Matrix, and TODAM models. Unpublished manuscript, University of Queensland, St. Lucia, Queensland, Australia.

Kučera, H., \& FrancIs, W. N. (1967). Computational analysis of present-day American English. Providence, RI: Brown University Press.

SMITH, S. M. (1985). Environmental context and recognition memory reconsidered. Bulletin of the Psychonomic Society, 23, 173-176.

Smith, S. M., Glenberg, A. M., \& BJork, R. A. (1978). Environmental context and human memory. Memory \& Cognition, 6, 324-353.

\section{APPENDIX \\ General Expressions for the Variances in the SAM Model and Other Global Matching Models*}

The variability of the match of a same-context test item with the image in memory of that item is $v_{1}$, and the variability in the match between two different items is $v_{o}$. The covariance between a same-context item matching itself and matching another same-context item is $c_{1}$, and the covariance between two samecontext mismatches is $c_{o}$. We assume, in keeping with Gillund and Shiffrin (1984), that $x_{d}=p x_{s}$, where $p$ is a constant for all list items, so that the variance and covariance components involving different-context items can be expressed as multiples $\left(p\right.$ or $\left.p^{2}\right)$ of the variance and covariance components involving same-context items:

$$
\begin{aligned}
\sigma_{s}^{2}= & v_{1}+(k-1) v_{o}+2(k-1) c_{1}+(k-1)(k-2) c_{o} \\
& +p^{2}\left[k v_{o}+k(k-1) c_{o}\right] \\
& +2 k p c_{1}+2(k-1) k p c_{o}
\end{aligned}
$$

and

$$
\begin{aligned}
\sigma_{d}^{2}= & p^{2}\left[v_{1}+(k-1) v_{o}+2(k-1) c_{1}+(k-1)(k-2) c_{o}\right] \\
& +k v_{o}+k(k-1) c_{o} \\
& +2 k p c_{1}+2(k-1) k p c_{o},
\end{aligned}
$$

where $\sigma_{s}^{2}=$ variance of a same-context old-item matching strength and $\sigma_{d}^{2}=$ variance of a different-context old-item matching strength.

Note that in both expressions line 1 contains the variance and covariance components for the same-context list, line 2 contains the components for the different-context list, and line 3 contains the covariances where one item comes from one list and the other item comes from the other list. By comparing these variances, it is clear that $p^{2} \sigma_{s}^{2}<\sigma_{d}^{2}$.

*See Humphreys, Pike, Bain, and Tehan, 1987.

(Manuscript received for publication October 17, 1987.) 